\title{
Reining in public spending on health care
}

$\mathrm{T}$ he amount of public money devoted to health care in Canada is expected to grow by only $2.9 \%$ in 2012 , a far cry from the $7 \%$ annual growth seen consistently for years until 2010.

"That's the real trend that stood out for us this year. ... That is the lowest rate since the mid-90s," says Christopher Kuchciak, manager of health expenditures at the Canadian Institute for Health Information (CIHI), which, on Oct. 30, released the report National Health Expenditure Trends, 1975 to 2012 (https://secure.cihi.ca/free_products /NHEXTrendsReport2012EN.pdf).

"Is this something we will continue to see?" says Kuchciak. "Or is it a temporary blip?"

Total health care spending in 2012, in both public and private sectors, is forecast at $\$ 207.4$ billion, or $11.6 \%$ of the country's gross domestic product (GDP). That again reflects the slowing of growth in health care spending, which amounted to $11.9 \%$ of the GDP two years ago.

"Most provincial governments are trying to contain costs. ... In the mid90s, it was about closing hospital beds and laying off health care workers. Now it's finding efficiencies, providing health care to meet the needs of the population but seeing that health care evolves to provide services in a costeffective way," says Kuchciak. "What I found interesting about the slowing down in spending growth is that everyone is using a different mechanism to achieve that objective."

Those efforts often target the biggest three health care expenditures: hospitals ( $\$ 60.5$ billion in 2012 , up $3.1 \%$ ), drugs ( $\$ 33$ billion in 2012, up 3.3\%) and physician services $(\$ 30$ billion, up $3.6 \%)$. Combined, these account for about $60 \%$ of all health expenditures.

Spending on drugs has been on the decline in recent years, thanks in part to blockbusters going off patent and a subsequent increase in availability of lower-priced generics. Though the

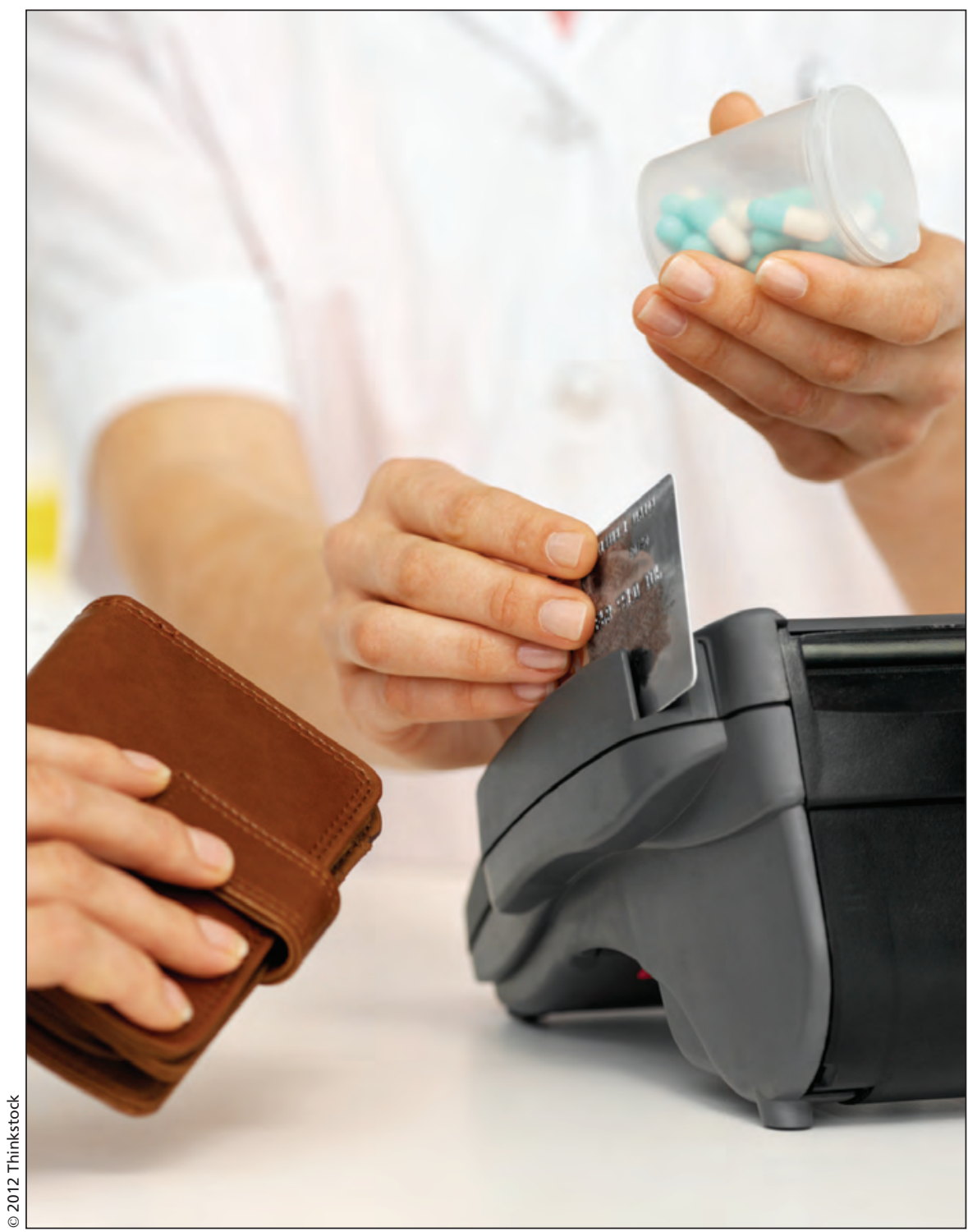

Direct consumer out-of-pocket payments for drugs and other health outlays are expected to rise $4.6 \%$ in 2012 , as compared with $2.6 \%$ in public sector outlays for health.

growth rate of payments to physicians has been slowing as well, some jurisdictions would like it to decline even further.

"Because physician payments have been outpacing the other two categories over the past five years, for some provinces that is an area of focus for them," says Kuchciak.

The report indicates that there continues to be substantial variations in provincial spending on health care. At the top end, there's Newfoundland and Labrador, and Alberta, which spend $\$ 7057$ and $\$ 6754$ per person, respectively. The lowest rung is occupied by Quebec, with a per capita health expenditure of $\$ 5469$, though British Columbia, at $\$ 5700$, is close to the bottom as well.

The financial strain of providing health care also takes a varying toll on 
available provincial resources. For instance, though Alberta ranks high in per capita spending, health care accounts for only $8.6 \%$ of the provinces GDP, the lowest rate of any province. On the other end is Prince Edward Island, which spends $17.4 \%$ of its GDP to tend to the health needs of its residents, though this still trails the territory of Nunavut, at $23.2 \%$.

There are several reasons for the diversity in provincial health expenditures, including age distributions, varying health needs of different populations and differing compensation schemes for health care workers, the report states. In general, though, two types of people put the largest dents in provincial health budgets: infants and seniors. A person under age one costs an average of $\$ 9264$ per year, dropping off dramatically to $\$ 1341$ once they enter the 1-14 age range. Of course, these numbers pale in comparison to those for Canadians over the age of 80 , who require a whopping \$20 113 in annual health care expenditures.

Still, the aging of Canada's population has a surprisingly modest overall impact on health care budgets, contributing a mere $0.9 \%$ to total spending growth. "The issue around population is that the speed at which it has an impact, if the trends continues at around $1 \%$ a year, is such that the health care system has time to evolve," says Kuchciak.

Overall, Canada spends \$5948 annually on health care for each citizen, up $2.2 \%$ from 2011. That puts Canada in the top quarter of countries in the Organisation for Economic Co-operation and Development (OECD), with similar per capita numbers as Denmark, Austria and Germany. The United States stands alone far above all other nations, spending US\$8233 per person, with Turkey
(US\$913) and Mexico (US\$916) pulling up the rear.

In terms of the split between health care paid for through taxes, or directly out of consumer pockets, public funds account for about $70 \%$ of the money spent on health care in Canada. In turn, hospitals and physician payments account for most of that money. Payments for drugs and nonphysician services account for the bulk of direct consumer spending. Though the growth of private sector outlays (4.6\%) in 2012 is expected to outpace that of the public sector $(2.9 \%)$, the public-private ratio has been stable for some time.

"The 70-30 split, it has remained constant," says Kuchciak. "In terms of that $70 \%$ share, relative to other OECD countries, we are in lower share of the spectrum." - Roger Collier, CMAJ

CMAJ 2012. DOI:10.1503/cmaj.109-4333 